\title{
Entrepreneurial university strategies in the UK context: Towards a research agenda
}

David Pickernell, Portsmouth Business School, University of Portsmouth, Portsmouth PO1 3DE, United Kingdom, david.pickernell@port.ac.uk

Alessio Ishizaka, Portsmouth Business School, University of Portsmouth, Portsmouth PO1 3DE, United Kingdom, Alessio.Ishizaka@ port.ac.uk

Shuangfa Huang, Portsmouth Business School, University of Portsmouth, Portsmouth PO1 3DE, United Kingdom, shuangfa.huang1@ port.ac.uk

Julienne Senyard, Griffith Business School, Griffith University, Nathan QLD 4111, Australia, j.senyard@griffith.edu.au

\begin{abstract}
Purpose - Prior research shows that universities differ in the knowledge exchange (KE) activities they pursue, but little is known about universities' strategies regarding their portfolio of KE activities. The purpose of this study is to explore the KE strategy of UK universities in specific relation to their portfolio of KE activities with small and medium-sized enterprises.

Design/methodology/approach - Based on the 2015-2016 Higher Education Business and Community Interaction Survey (HE-BCI) data set, this study employs the Preference Ranking Organization METHod for the Enrichment of Evaluations (PROMETHEE) to assess the KE activities from 162 UK higher education institutions.

Findings - The study reveals that entrepreneurial universities valorize university knowledge assets through five SME-focused KE activities most beneficial to measuring the entrepreneurial university. It also uncovers four different archetypal categories (groupings) of universities based on their strategic focus of KE activities.

Originality/value - This study contributes to the Entrepreneurial University literature by considering universities' overall KE portfolio rather than examining individual KE activity in isolation. It provides a clearer understanding of universities' KE strategies that help define and delineate Entrepreneurial Universities regarding their range, focus, and the combination of KE activities.
\end{abstract}

Keywords Entrepreneurial University, Third Sector Activity, Knowledge Exchange Strategy, Small and Medium-Sized Enterprises, PROMETHEE, Ranking of University

Paper type Research paper 


\section{Introduction}

Increased competition exists for universities, as a consequence of decreasing higher education funding from the government (Lambert, 2003; Martin, 2012; Mowery et al., 2015). Simultaneously, universities are increasingly tasked with contributing to the broader development of the economy and society (Perkmann et al., 2013; Sánchez-Barrioluengo, 2014). Under greater pressure to tackle the challenges of the knowledge economy (Charles et al., 2014; Miller et al., 2014) this places increasing importance on the "Entrepreneurial University" concept.

Broadly, Entrepreneurial Universities have been defined as universities that pursue a third mission beyond their traditional missions of teaching and research (Sam and Sijde, 2014). Defined more narrowly, Etzkowitz et al., (2000) define Entrepreneurial Universities as those that engage in third mission activities to improve regional or national economic performance as well as the university's own financial position. Third mission activities, also known as knowledge exchange (KE) activities or entrepreneurial activities (Philpott et al., 2011), are in the UK measured under the term Third Sector Activity (TSA). Since these activities have profound economic and social impacts (Guerrero et al., 2016; Fini et al., 2018), extensive studies have explored determinants of KE activities (D'Este and Patel, 2007; Guerrero and Urbano, 2012; Huggins et al., 2012; Galán-Muros and Plewa, 2016; Hmieleski and Powell, 2018).

Clearly, however, universities are heterogeneous organisations, there being 162 higher education institutions in the UK context for example, differing significantly in background and characteristics. Within the literature analysis of UK universities has tended, however, to follow relatively simple, usually dichotomous, evaluations in regards to the Entrepreneurial University. Morgan (2002), for example, classified this dichotomy between 'elite' and 
'outreach' universities, overlapping with Hewitt-Dundas's (2012) Low Research Intensive (LRI) / High Research Intensive (HRI) definition in which LRI/outreach universities were engaged in far more human (social) capital development than HRI/elite universities whilst HRI/elite universities were able to generate far more income from their research and were provided with far more funds for that research. This essentially dichotomous approach has also been adopted in more recent work. Fuller et al., (2017), for example, constructed indexes based on universities existing along (indexed) continuums in terms of the extent to which they can be seen as more entrepreneurial (as defined by focus on a narrower range of activities, more likely primarily for their own benefit) or enterprising (more broadly and balanced in their focus in activities that both benefit themselves but also the economy more widely).

Despite growing interest among academics and policymakers in entrepreneurial universities (Etzkowitz et al., 2000; Audretsch, 2014; Guerrero et al., 2016), the variety and connectivity of their strategies regarding the KE portfolio (i.e., the mix of KE activities universities pursue) has received relatively limited attention (Sengupta and Ray 2017a). For example, prior studies tend to focus on comparing the individual $\mathrm{KE}$ activity separately without considering the portfolio of KE activities pursued by universities (Hewitt-Dundas, 2012; Abreu et al., 2016). Even where multiple KE activities have been analysed together, as in Fuller et al., (2017) this has concentrated on the overall resultant index score and university ranking, rather than analysing the range of ways similar rankings may be achieved by different universities.

This paper argues that examining individual KE activities in isolation, or considering only the overall KE "score", however constructed, without also considering the overall KE portfolio, gives only a partial picture, because universities engage in sets of KE activities rather than pursuing a single activity alone. Literature has highlighted that universities are heterogeneous institutions varying in objectives and strategic priorities with regards to the types of partners they engage with, as well as the range of TSA they pursue (Kitagawa et al., 2016). Examining 
universities' KE portfolio is critical as it can shed lights on the range of activities universities pursue, and thus help to uncover universities' KE strategy. In other words, universities' strategic priorities in KE can be identified through examining the combinations of activities they undertake.

The combinations of activities they undertake have a further, specific importance when applied to interactions with SMEs. Giuliani and Arza's (2009) research shows that the value of universities' TSA can partly be determined by the knowledge base of those receiving university knowledge, highlighting the key importance of firms' absorptive capacity (Clifton et al, 2010) in this debate. This is often an issue with regards to smaller firms in particular, because "SMEs find it difficult to engage with HEIs for a host of different reasons, not least the lack of resources to engage, the lack of capabilities to identify the right partners, and a lack of awareness of the benefits." (PACEC, 2012, p. 32). This therefore gives additional importance to the interactions between universities and HEIs that do take place, and increases the importance of analysis of these.

Clifton et al., (2010), analysing contributions of a range of actors in SME innovation creation and dissemination, also highlight that because the level of UK firm-UK university cooperation was often low, firms also required a certain level of absorptive capacity (through their own innovation activities), to provide legitimacy prior to being able to beneficially cooperate with a university. All of this raises potential important questions of WHO universities engage with through their TSAs, as well as WHAT activities this is focused through, in helping to better understand the strategies that lie behind the Entrepreneurial University concept. Specifically, how is the degree and type of engagement with SMEs relevant in this debate?

To put in context, whilst recent empirical work indicates that universities differ in the KE strategy they adopt, with some universities emphasising a broad range of KE activities while 
others are more selective on the activities they pursue (Kitagawa et al., 2016; Sengupta and Ray, 2017a), the existing evidence is based only on a small number of universities. We also still lack a holistic understanding of how the strategy of KE portfolio varies amongst universities in the UK specifically. Research suggests that universities make strategic choices by growing certain KE activities while neglecting others (Day and Fernandez, 2015). There is, however, currently little research explicitly about the strategies of universities regarding their KE portfolio in terms of simultaneously analysing the size, scope and focus of this portfolio. This is particularly apparent with regards to universities' KE strategies with regards to SMEs. In the UK context, this may partly be because SMEs have historically only accounted for a relatively small proportion of the total incomes generated from universities' KE activities (HEBCI Report, 2017).

We focus specifically on universities' KE activities with SMEs because we believe it to be a better Entrepreneurial University focused measure of the strategic choices of universities generally than KE activities overall. It simultaneously captures Etzkowitz et al's (2000) definition of university activities that simultaneously improve university and regional or national economic performance, whilst also broadly fitting many aspects of the "enterprising university" definition described in Fuller et al., (2017). Another reason to focus on SMEs is that the majority of English universities having established infrastructure to provide support for SMEs (HE-BCI report 2017), implying their extent of engagement with SMEs are more likely to be a function of their strategic decisions. By contrast, it may be more challenging for some universities to attract and collaborate with large organisations due to constraints in resources and capabilities (Kitagawa et al., 2016).

Furthermore, SMEs represents an increasingly important source of revenues for universities (HE-BCI Report, 2017). SMEs has been identified as the most frequent target for KE activities (PACEC/CBR, 2009). This is not surprising given that universities are increasingly 
incentivised to interact with SMEs. For example, the KE incomes generated from SMEs being double weighted in the allocation of third stream funding by the Higher Education Funding Council for England (Rosli and Rossi, 2016). Evidence has also shown that universities interact with SMEs to a greater extent than large firms (Huggins et al., 2012).

Accordingly, the purpose of this study is to explore the KE strategy of universities in the UK in specific relation to their portfolio of KE activities with SMEs. In so doing, this study identifies groups of universities sharing similar KE strategies in their interaction with SMEs, upon which more detailed analysis of the reasons behind these choices can be built. We adopt a holistic approach by using individual universities as the unit of analysis and considering the KE portfolio of universities with SMEs. Based on the 2015-2016 HE-BCIS dataset, we identified universities' incomes from each KE activities they pursue. The incomes are then used as proxy to represent universities' relative strategic focus on each KE activity. As such, the present study concerns the outcomes from universities' KE strategy rather than their strategic choices which may or may not be realised.

In order to undertake ranking universities according to a range of $\mathrm{KE}$ activities whilst simultaneously identifying and illustrating groups of universities sharing similar portfolios in terms of these outcomes from their KE strategy, it is necessary to use a different approach to those used in studies such as Fuller et al (2017). Preference Ranking Organization METHod for the Enrichment of Evaluations (PROMETHEE) is a multicriteria method that employs visualization software that, with few parameters, creates non-technical, user-friendly visualization of results (Brans 1982; Brans and Vincke 1985; Nemery et al. 2012). The evaluation of each criterion can be expressed in their natural units, also eliminating problems relating to scaling, obviating the need for normalization of scores, avoiding rankings relying on the selected normalization method (Tofallis 2008, Ishizaka and Nemery 2011), or the log based approach highlighted in Fuller et al (2017). Instead the decision-maker defines a 
preference function generally characterized by an indifference and preference threshold. PROMETHEE is also able to be linked to Graphical analysis for interactive aid (GAIA), allowing two dimensional representation of individual decision-maker preferences (Brans and Mareschal 1994). In this research, all included universities are able to be represented and then compared on a single GAIA diagram, which compares favourably to previous approaches (such as example Fuller et al, 2017) which require multiple diagrams to undertake the same types of processes.

The rest of the paper is structured as follows. The next section evaluates the existing literature for university KE activities in terms of the different types of activities and partners they can engage with, focusing on the heterogeneous strategies that are possible. From this research questions are developed. The PROMETHEE methodology is then outlined, followed by the results. These are then discussed and compared with the extant literature. Finally, in the conclusions, contributions are identified, limitations explained and future research opportunities discussed.

\section{Literature review}

\subsection{The heterogeneity of universities and their KE activities}

While Etzkowitz et al., (2000, p. 313) assert "the 'entrepreneurial university' is a global phenomenon with an isomorphic developmental path", recent research suggests no best type of entrepreneurial university exists (Bronstein and Reihlen, 2014) because of considerable differences between higher education systems across different countries and even between universities in the same educational system (Bonaccorsi et al., 2007; Philpott et al., 2011; Sánchez-Barrioluengo, 2014). Indeed, based on a meta-synthesis of twenty-seven case studies on entrepreneurial universities across different national contexts, Bronstein and Reihlen (2014) 
found that universities can be categorised into several different types depending on their primary focus.

Previously, UK universities have been categorised into types such as new versus old, researchoriented versus teaching-led, and Russell Group versus non-Russell Group. Research-oriented universities have significantly higher levels of research outputs than those that are teaching-led (Abreu et al., 2016). It can thus be expected that universities have different levels of resources and capabilities that may influence their engagement in KE activities.

Indeed, evidence suggests that universities differ in their engagement in KE activities. For example, Hewitt-Dundas (2012) showed that HRI universities generated higher KE incomes from SMEs in contract research and consultancy but lower revenues in courses for business and community than LRI universities. Likewise, Huggins et al., (2012) showed that older universities have a higher tendency than new universities to interact with different types of organisations for KE activities. Similarly, Abreu et al., (2016) found that research-intensive universities (i.e., the 24 Russell Group universities) differ from teaching-led universities (i.e., 126 non-Russell Group) in the KE type of activities pursued, in particular exhibiting higher levels of licensing, spin-out, and contract research activities.

While these studies have contributed to our understanding of how universities differ in KE activities, there are limitations remain to be addressed. In addition to differences between universities in different groups (e.g., Russell versus non-Russell Group), substantial differences also exist within the same group (Sengupta and Ray, 2017a). Within group differences concerning KE activities, however, are largely unexplored in the literature. Furthermore, prior research often examines $\mathrm{KE}$ activities in isolation without considering the KE portfolio. This is problematic because universities often pursue a set of KE activities and need to balance the different KE activities they undertake (Day and Fernandez, 2015). Examining individual KE 
activities in isolation therefore provides an incomplete picture of the overall KE strategies of universities.

\section{$2.2 \mathrm{KE}$ strategies}

The KE strategies of universities entail at least four key elements: the range of KE activities they pursue, the relative emphasis they put on each activity within this KE portfolio, the type of partners they engage with, and the geography (e.g. regional, national, and international) they are focused on when engaging with partners. As Kitagawa et al., (2016, p.736) noted, "each university creates its own approaches and models of third mission by targeting different areas of activities, partners and geographical areas."

KE activities can take place through a wide range of channels including patenting, licensing, spin-offs, contract research, collaborative research, consultancies, continuing professional development (CPD) and facilities and equipment related services (Perkmann et al., 2013; Abreu et al., 2016). KE channels such as patenting, licensing, and spin-offs are often used by universities to exploit the intellectual property they generated (Abreu and Grinevich, 2013). Since KE activities through these channels are less compatible with the traditional role of academics (Louis et al., 1989), they are often considered more entrepreneurial. Conversely, KE activities through channels such as contract research, collaborative research, and consultancies are seen to be more aligned with the traditional academic culture and considered less entrepreneurial (Louis et al., 1989). These boundaries may be, however, increasingly blurring in relation to the entrepreneurial university concept as TSA revenues become more important.

Universities may adopt either a broad or a focused strategy for KE portfolio (Kitagawa et al., 2016; Sengupta and Ray, 2017a). They may pursue a broad strategy, engaging with external organisations via a wide range of channels, for several reasons. First, a broad KE strategy may allow universities to generate revenues through multiple KE channels. Other things being equal, 
universities using a broad range of KE channels should be better positioned to address the specific needs of individual organisations and generate greater incomes from diverse sources (Olmos-Peñuela et al., 2014; Ramos-Vielba et al., 2016). Second, it allows universities to develop diverse knowledge bases and capabilities to help bridge gaps between scientific research and application (D'Este and Patel, 2007). Third, it enables universities to enhance their research base. Since the knowledge flow between universities - industries interactions tend to be bi-directional rather than unidirectional, universities can also gain considerable insights from interactions with industries (D’Este and Patel, 2007). For example, KE activities such as collaboration and contract research may lead to the development of new knowledge that contributes to universities' research base. Recent evidence also suggests that universities' past research output (both quality and quantity) positively impact their knowledge transfer activities (Sengupta and Ray 2017b).

Conversely, some universities may pursue a narrower KE strategy, where they have comparative strengths to compete effectively in the competitive education sector. For example, universities that focus on $\mathrm{KE}$ activities where they have a relative advantage are more likely to achieve above average growth in their KE incomes (Day and Fernandez, 2015). Furthermore, the disciplinary mix of universities may also influence their strategic choices to focus on certain KE activities over others. Since universities may have a very different disciplinary mix as determined by the faculties and schools they are composed of (Bonaccorsi et al., 2007), the educational activities and research outputs should vary between them. Such a difference can impact the forms and range of KE activities universities pursue. For example, patenting and licensing activities are more relevant to certain academic disciplines (e.g., biosciences) than others (Mowery et al., 2015). The decisions to focus on a smaller set of KE channels may also, of course, partly be the result of constraints on the availability of resources and capabilities. For example, universities that are relatively small in scale may lack the resources and 
capabilities to pursue a broad KE strategy. Likewise, in comparison with old universities, new universities tend to have a disadvantage in pursuing diverse KE activities because they are much more constrained in terms of internal resources than established universities (Huggins et al., 2012; McCormack et al., 2014) as well as external relationships.

It should be noted, however, that even for universities that adopt a broad KE strategy, the relative importance of each $\mathrm{KE}$ channel may differ between individual universities. For example, some universities may generate higher proportions of income from certain channel(s) and lower from others (Day and Fernandez, 2015), demonstrating that not all universities emphasise the same channels in their KE strategy (Sengupta and Ray, 2017a). Evidence also suggests that incomes from patenting, licensing, and spin-offs activities represent a relatively small proportion, a large percentage of revenues instead generated through contract research, collaborative research, and consultancy (HE-BCI Report, 2017).

The type of partner universities interact with for KE activities may include SMEs, large firms, and other non-commercial organisations. Some universities (often low research intensity) have a greater strategic focus on SMEs, while others (often high research intensity) tend to emphasise large firms (PACEC/CBR, 2009). Evidence has shown that, for both established and new universities, SMEs are the predominant type of organisation they interact with (Huggins et al., 2012). This may partly be because universities generally are less likely to be constrained by resources or capabilities to engage with SMEs (Kitagawa et al., 2016). Indeed, irrespective of their relative size, age, and research quality, most universities in the UK have established the infrastructure to engage with SMEs, partly supported by the funding from government initiatives (HE-BCI Report, 2017). Given that most universities have capabilities to interact with SMEs, it is reasonable to expect their extent of engagement with SMEs to be more a function of their strategic choice than resource-related necessity than it would be for $\mathrm{KE}$ 
activities more generally. As such a focus on SME engagement therefore has the potential to give a better understanding of the range of Entrepreneurial university strategies.

It must also be acknowledged that the regions the universities are embedded within can also impact their KE strategies. In England, for example, Local Economic Partnerships (LEPs) research has shown that "there are significant variations in the population of SMEs across LEPs both in terms of their number, sectoral composition, productivity and technological intensity" (Bonner et al., 2015, p. 3). This implies that the demand of SMEs for specific KE activities should vary substantially between different regions. This may be for a number of reasons, related to numbers of SMEs within a region, but also their sectoral breakdown and growth ambitions. For example, SMEs in high-technology sectors or knowledge-intensive business services may have a higher demand for collaborative research or contract research (Bonner et al., 2015), whilst higher growth oriented firms are both more likely to engage in international markets (Mason and Brown, 2013; BIS, 2010), where innovation is more important, and are likely to be more open to business support and collaboration (Bonner et al., 2015). Conversely, regions lacking these types of SMEs may also be the ones where university KE activity is promoted more strongly by government (Cooke, 2003). Indeed, recent empirical evidence suggests that "academics in uncompetitive regions are more intensively engaged in entrepreneurial activities but generate less income from them than their counterparts in competitive regions, suggesting that there are differences in the income-generating capacity of academics across regions" (Zhang et al., 2016, p. 257). Partly related to this universities will have different strategies in relation to the geographic scope of the partners they interact with for KE, some universities more likely to engage with business at the regional level, while others are more likely to engage with business at national or international level.

This review of the literature therefore identifies a need for tools for Entrepreneurial Universities to better understand and evaluate their own and other universities' KE activities and consequent 
strategic profiles, particularly given their need to increasingly focus their engagement strategies in this area as a result of increased competition and constrained resources from other sources. In this research we are therefore interested in the following questions:

- How do entrepreneurial universities valorize university knowledge assets in terms of SMEfocused KE activities that can be seen as most beneficial to measuring the entrepreneurial university?

-What entrepreneurial university models/archetypes can be identified and classified in terms of these SME-focused KE activities?

-What are the most relevant KE activities (both singular and in combination) that universities are using, in relation to the entrepreneurial university concept as it relates to interactions with SMEs?

-Are there specific SME-focused entrepreneurial university models / archetypes that are more likely to influence regional economic development in terms of shaping entrepreneurial ecosystems?

\section{Method}

\subsection{PROMETHEE}

The Preference Ranking Organization METHod for the Enrichment of Evaluations (PROMETHEE) has attracted increasing attention in the literature (see Behzadian et al., 2010 for a recent review). For example, prior research has applied it to evaluate business incubators (Schwartz and Göthner, 2009), project selection (Halouani et al., 2009), and, important for this paper, the strategic goals of education institutions (Živković et al., 2017). 
Information within a Criterion- As with any multicriteria decision problem, we consider a set of $m$ possible actions or alternatives $A=\left\{a_{1}, a_{2}, \ldots, a_{m}\right\}$ which are evaluated on a set of $n$ criteria $C=\left\{c_{1}, c_{2}, . ., c_{n}\right\}$. For each criterion, and for each ordered pair of actions, the decision maker expresses his/her preference by means of a preference degree. The preference degree $P_{i}(a, b)$ indicates if an alternative $a$ is preferred or not to alternative $b$ on the criterion $c_{i}$. The preference degree is obtained using the preference function. Several typical shapes are proposed (Brans and Vincke 1985) for the preference functions like the linear, the step or Gaussian preference function.

Aggregated Preference Functions- In order to evaluate how much action $a$ is preferred to $b$ over all the criteria, the preference index $\pi(a, b)$ is calculated with a weighted sum (1) of the preference degrees $P_{i}(a, b)$. The weights $w_{i}$, calculated represent the importance of each criteria in the decision.

$$
\text { (1) } \quad \pi(a, b)=\sum_{i=1}^{n} P_{i}(a, b) \cdot w_{i}
$$

where $P_{i}(a, b)$ is the score of the preference function, $w_{i}$ the weight of criterion $c_{i}$ and $n$ the number of criteria.

Outranking Flows- As each action is compared with $m-1$ other actions, two flows can be defined with (1):

The Positive flow:

(2) $\quad \Phi^{+}(a)=\frac{1}{m-1} \sum_{x \in A}^{m} \pi(a, x)$

...with $m$ being the number of actions of the set $A$

This score represents the global strength of action $a$ in comparison to all the other actions. It is this score that has to be maximized. 
The Negative flow:

(3) $\quad \Phi-(\mathrm{a})=\frac{1}{m-1} \sum_{x \in A}^{m} \pi(x, a)$

...with $m$ being the number of actions of the set $A$

This score represents the global weakness of $a$ in comparison to all the other actions. It is this s score that has to be minimized.

Ranking- The complete ranking of PROMETHEE II is given by the net flow:

(4) $\quad \Phi(a)=\Phi^{+}(a)-\Phi^{-}(a)$

The higher the net flows, the better the rank of an action. A fuller discussion on net flow scores can be found in Brans and Mareschal (2005) and Mareschal et al., (2008).

The score produced for each university is entirely relative to the pool of other universities. The score is relative and sums to 0 . This means that if we have say only two universities and one has a score of 0.5 , then the second will have a score of -0.5 .

\subsection{Visualizing the results - Graphical analysis for interactive aid (GAIA)}

The aim of the GAIA method is to represent, on a two dimensional view, as much as possible the decision-maker's preferences and its implications (Brans and Mareschal 1994). For this purpose, a plane in the hyperspace is found via principal component analysis (PCA) of the matrix $\Phi$. In the PCA, the variance-covariance matrix of the decision problem, noted $\mathrm{C}$, is first calculated. This matrix can be obtained by using the following relation:

(5) $n \mathrm{C}=\Phi^{\prime} \Phi$

...where $\quad \mathrm{C}:$ variance-covariance matrix

$\Phi^{\prime}:$ the transposed matrix of $\Phi$ 


\section{$n$ : positive integer}

Then, two eigenvectors, noted, $\vec{u}$ and $\vec{v}$ are selected such as they have the greatest eigenvalues $\lambda_{1}$ and $\lambda_{2}$. These two eigenvectors are orthogonal $(\vec{u} \perp \vec{v})$ and define the best plane, called the GAIA plane, to use for the projection of the actions (the $a_{i}$ points) while minimizing the loss of information (Brans and Mareschal 1994).

Every action of the decision problem will be projected in this plane and its coordinates are obtained as follows:

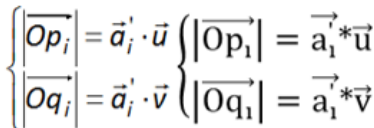

$$
\begin{aligned}
& \text {... where } \vec{a}_{i}^{\prime} \text { : transposed row } i \text { of matrix } \Phi
\end{aligned}
$$

In order to represent the intra criteria information, each criterion $f_{j}$ will be projected to $c_{j}$ on the GAIA plane. The angle between the projections of two criteria is a measure of similarity or conflict between the criteria. The smaller the angle, the more similar two criteria are. A large angle means conflicting criteria.

Finally, the information on the weights chosen by the decision-maker can be added by finding the projection of the weights vector: $\vec{w}:\left(w_{1}, w_{2}, \ldots, w_{j}, \ldots, w_{k}\right) \vec{w}:\left(w_{1}, w_{2}, \ldots, w_{j}, \ldots, w_{k}\right)$. The obtained vector is called a Decision Stick $\vec{D}$, and represents the decision-maker's priorities:

$$
\vec{D}:(\vec{w} \cdot \vec{u}, \vec{w} \cdot \vec{u})
$$

The GAIA plane facilitates the decision aid process as easy conclusions can be drawn visually. Near actions on the plane will often have very similar rows in the variance-covariance matrix $\Phi$. The decision-maker can thus easily identify actions with similar or opposite performances. Moreover, the decision-maker can compare criteria since their position on the plane is an 
indication of their conflicting or correlated behaviour. Their length represents their distinguishing power between actions. A wash criterion has a short length; a discriminating criterion has a long length.

\subsection{Data used}

This research evaluates the following variables, all taken from the 2015-2016 HE-BCIS dataset, expressed in $£$. for the eight $\mathrm{KE}$ variables contained in the dataset that were also identified from the literature as relevant to the Entrepreneurial University context, and where an explicit focus on SMEs could be identified or implied:-

- Income from Continuous Professional Development with SMEs

- Income from Shares sold in spinouts

- Income from software licence income from SMEs

- Income from non-software licence income with SMEs

- Income from Consultancy with SMEs

- Other Intellectual Property (IP) Income with SMEs

- Income from Contract Research with SMEs

- Income from Facilities and Equipment Related Services with SMEs.

\section{Results}

In terms of the results, these can be presented in a number of ways. The most obvious, and traditional, is in the form of a ranking of University KE Activity with SMEs, based on the PROMETHEE analysis itself, illustrated in the table below which, for reasons of brevity, shows the first 30 universities in the index.

$* * *$ Table $1 * * *$ 
This ranking generates an order consistent with alternative rankings (albeit in slightly different contexts using different methods) conducted by, for example, Fuller et al (2017). However, because PROMETHEE is specifically designed to focus on the strategies employed via the way in which the scores are generated, supported by the additional visualisation techniques employed, additional information relevant information is generated as discussed below. For example, the stacked bar chart below (which, for brevity only shows the first 30 universities in the index) indicates where low performance on one criterion can be totally compensated and masked by higher performance on another criterion.

$$
* * * \text { Figure } 1 * * *
$$

Figure 1 illustrates the university ranking in decreasing order according to their net score (sum of positive and negative). This ranking is the same as in Table 1. It shows a stacked bar chart of the contribution of each evaluation criterion to the global score. Because PROMETHEE is a partial compensatory method, low scores for one variable cannot be fully compensated by high scores. For example, the Anglia Ruskin (A4) score is very reliant on consultancy income from SMEs and would appear higher in the rankings without PROMETHEE being able to partially compensate for this. Indifference thresholds define the minimum necessary for each criterion to be achieved in order to start to accumulate a positive flow. The preference threshold, at the other end, gives the maximum allowed to be accumulated in the positive flow. This therefore partially compensates in the overall ranking for universities strategically concentrating only or mainly on that measured criteria. A negative score means that they are below average overall, whilst a positive score indicates an above average overall performance.

In general terms this allows identification of the relevant KE strengths (that could be used by university management for marketing promotion) and weaknesses (that can be used for policy development focus) of each university. For example, A12 (Birmingham City University) could improve on the contract research income they could generate and as a result improve their 
score. Many universities also have a very small bar, which indicates that they need to improve on all evaluation criteria.

The GAIA visual technique provides more information than simple ranking, through the identification of the criteria contributing most to the differences between universities in terms of their rankings, where criteria are more closely correlated with each other, and also a visual means of identifying groupings of universities as defined by similar outcomes from universities' KE strategies.

$$
* * * \text { Figure } 2 * * *
$$

Figure 2 focuses on the centre of the GAIA plane. Consultancy for SMEs, CPD for SMEs Software licence income, non-software licence income and contract research are the criteria that have the best discriminating power for evaluating Universities because they have longer arrows. The other criteria, share in spinouts, other IP income and Facilities and equipment related services in contrast, have low discriminating power (short arrow), which indicates that universities have very similar values for these activities. Indeed, many universities are not undertaking these activities at all.

Where the arrows are pointing in the same direction, this indicates that the criteria are positively correlated. The closer the lines are to each other the stronger the correlation. Therefore, other IP income, facilities and equipment related services, Consultancy for SMEs, and CPD for SMEs are correlated with each other. There is another set of correlations between Software licence income, non software licence income, sales of shares in spinoffs, and Contract research.

By way of contrast, the arrow for $C P D$ for SMEs is more than $90^{\circ}$ different to software licence income, indicating that universities generating strong income performance from CPD activities do much less well in terms of software licensing and vice versa. Another way to look at this is 
the larger the angles between variables, the higher the degree of potential policy tension between the desired outcomes, with potential trade-offs between these groups of policy aims, since they are less strongly mutually supportive than where variables are more strongly correlated.

\section{Discussion}

\subsection{Archetypes of universities based on SME-focused KE activities}

Specifically focusing on the research questions identified, it can clearly be seen that entrepreneurial universities valorize university knowledge assets through five SME-focused $\mathrm{KE}$ activities most beneficial to measuring the entrepreneurial university, namely Consultancy for SMEs, CPD for SMEs Software licence income, non-software licence income and contract research. These are the criteria identified as having the best discriminating power for evaluating Universities because they have longer arrows. They also indicate, at an individual level, a broad range of ways in which universities are generating value from their knowledge assets in relationships with SMEs.

Figure 3 identifies where each university sits on the GAIA plane, both in terms of the activities that it focuses upon and which other universities it is closest to, the precise position of each university being a combination of the strength (or weakness) in overall activities and also the activity/activities it is most strongly associated with. Using figure 3, four different broad archetypal categories (groupings) of entrepreneurial university models/archetypes can be identified and classified in terms of these SME-focused KE activities. These are visually identified on the GAIA plane and defined in terms of position on the diagram and by the correlations between the criteria as follows:- 
- Weak External Entrepreneurial Income generating Activities with SMEs (having negative values). Examples include the University of Winchester and University of Chichester

- “Teaching Related Focus": CPD / Consultancy / Facilities focused / (e.g. Liverpool $\left.\left(6^{\text {th }}\right)\right)$, Salford (ranked $\left.12^{\text {th }}\right)$, Anglia Ruskin $\left(13^{\text {th }}\right)$ and York $\left(14^{\text {th }}\right)$

- "IP Exploitation Related Focus" Software licence income / non software licence income / Contract research, and sales of shares in spinoffs focused (Oxford University (ranked $\left.1^{\text {st }}\right)$, University College London $\left(2^{\text {nd }}\right)$, Dundee University $\left(9^{\text {th }}\right)$, University of Aberdeen (10th)

- "Broad Focus" (e.g. Southampton $\left(3^{\text {rd }}\right)$, Cambridge $\left(7^{\text {th }}\right)$, Nottingham (11th)

$$
* * * \text { Figure } 3 * * *
$$

Identifying the most relevant KE activities (both singular and in combination) that universities are using in relation to the entrepreneurial university concept as it relates to interactions with SMEs, it can be seen that Universities with a narrower IP Exploitation Related focus (IPERF) are more likely to be found higher up the Entrepreneurial University rankings (Oxford University (ranked 1st), University College London (2nd), Dundee University (9th), University of Aberdeen (10th)). Overall, 6 of the top 10 places are taken by universities with this type of strategy, compared to 3 with a Broad Focus (BF) strategy. The fact that only one university with the narrower "Teaching Related Focus" (TRF) is placed in the top 10, suggests that the success of a narrow focus strategy is also dependent on which activities are focused on, the focused grouping having representatives that are much less prevalent in the Entrepreneurial University index, at least amongst the top ten.

If one looks at all the universities with positive scores, the picture becomes even more nuanced. Of the 49 universities with a positive score, whilst it is the 15 IPERF universities, which rely 
on a smaller number of key KE activities for their rankings, that have the highest average score, they have a slightly lower average ranking than the $11 \mathrm{BF}$ universities which generate their results from a wider range of activities. Also, whilst the TRF universities have the lowest average ranking and score, they are also the most prevalent grouping in the top 49, with 23 universities, and between these three groupings the differences in average scores and rankings are not significant.

This result also suggests a blurring of universities' KE strategies, with contract research in this analysis, previously seen as more broadly linked to academic engagement, in this study being more aligned with research commercialisation. Simultaneously, academic engagement and business and community- related services can be seen as part of one broader group of activities.

In comparison with previous approaches, there are also some interesting contrasts. For example, compared with the approach of Hewitt-Dundas (2012) it can be seen that whilst, as expected, there is a concentration of the old research intensive HRIs from the Russell Group in the IPERF cluster (with ten of the fifteen universities coming from the Russell Group), there are another seven in the more widely focused BF grouping (of the total of twelve), four in the TRF group and three in the cluster that would be characterised as Weak External Entrepreneurial Income (WEEI) generating in terms of their activities with SMEs. In comparison with Fuller et al (2017), the index of overall rankings are strongly correlated, both with the entrepreneurial university index (0.67) and even more so the enterprising university index (0.71). This lends support to the approach used in this study in that it is consistent with previous studies using different techniques, is most strongly related to a broader measure of enterprise supporting activities, but also is able to provide additional information in relation to different strategic foci that underlie the rankings.

\subsection{Implications for regional economic development}


The final research question, concerning whether there are specific SME-focused entrepreneurial university models/archetypes that are more likely to influence regional economic development in terms of shaping entrepreneurial ecosystems, is more complex. The results from this study suggest the ways universities engage in strategic choices tend to be within a small number of KE portfolios that vary significantly. In part this appears likely due to universities that emphasise KE activities aligned with their own internally driven advantages will likely achieve better outcomes for the university itself. However, there are also other, more subtle often geographic forces at play. For example, prior empirical evidence has shown a negative correlation between the incomes from contract research and CPD (Day and Fernandez, 2015), suggesting that universities that have high levels of contract research activities are less likely to have high levels of CPD. Previously it has been suggested that this may be due to the potential divide between research-intensive and teaching-led universities. For example, contract research is more research oriented, suggesting that it is more linked to the research intensity of universities, whereas CPD is more teaching oriented, implying that it is more related to how the university prioritises teaching. Whilst our results partly support this, as these activities are being employed in closely correlated sets of activities for different groupings of universities, high research intensive Russell group universities can also be found in both groups, as well as less research intensive. There are also the more broadly based universities (including Russell group universities) that undertake both sets of activities more evenly. More generally, the Russell Group universities traditionally defined as being research intensive can be found in all four of the groupings.

It is the universities with a narrower focus on higher research based activities, that are more likely to be ranked in the top 10 of this index, indicating that from the universities' point of view, it may be that a more niche focused strategy (particularly research commercialisation which leverages the intellectual property generated within the university) is more likely to be 
successful from the university's own point of view. It has also been highlighted previously that research commercialisation activities can contribute to regional economic development through the creation of new ventures and jobs (Fini et al., 2011), spin-offs positively impacting economic development (Guerrero et al., 2015), these KE activities directly contributing to society via the introduction of new products and services (Colyvas, 2007). Given the greater need for these activities to take place within entrepreneurial ecosystems that are able to absorb and use this knowledge then it might be expected that this particular archetype would work best in terms of regional economic development within stronger core regions. Looking at the LEP area covering London, for example, of the 7 universities with a KE focus (another 30 being part of the WEEI cluster), 2 fall within the TRF grouping, 1 within the BF group and the majority, 4, are designated as IPERF in nature.

Conversely, the other focused grouping, encompassing TRF activities (and universities Salford (ranked 12th), York (14th), Anglia Ruskin (13th) and Liverpool (6th)) includes activities that have received less attention than studies on research commercialisation. Indeed, the study by D'Este and Patel (2007) is among one of the first to consider activities such as contract research and consulting. This grouping also includes KE activities that can be seen as providing business and community related services, designed to support businesses and local communities, such as continuing professional development (CPD) and facilities and equipment related services. Through accessing universities' resources, organisations may consequently save the resources that are required to invest in their own facilities, extremely beneficial for SMEs given that they tend to be constrained by limited resources. This would suggest, therefore that this particular archetype would work best in terms of regional economic development in more obviously peripheral economic regions. In the South West of England, for example, only 2 of the 6 universities have a KE focus (the other 4 being WEEI) both of these part of the TRF group. For Liverpool whilst 4 of the 5 universities are part of the WEEI group, the one KE focused 
university is part of the TRF. In the North East also, whilst 2 of the universities are in the WEEI category, there are $2 \mathrm{KE}$ focused universities, both part of the TRF cluster.

It is between the core-periphery extreme, therefore, that one might expect the broad based entrepreneurial university archetype to be most relevant, but also potentially, more difficult to achieve, and therefore likely to be in more need of stronger internal and external drivers. The evidence here is broadly, but not wholly supportive of this. In England, the LEP covering Manchester, for example, has 1 BF university as well as 1 IPERF and 3 in the WEEI category. For the LEP covering Leeds also includes a BF university along with 4 in the WEEI category. In terms of GVA per head in the region in which the universities sit, within the 3 broad groupings of universities with positive scores, it is those with Software licence income / non software licence income / Contract research, and sales of shares in spinoffs focus that have the highest GVA per head average (£28054), with universities taking the CPD / Consultancy / Facilities focus where the GVA per head average is lowest (£23985), the broadly focused university grouping sitting between these two extremes (£27534).

In terms of external drivers, the government is clearly encouraging businesses to engage with universities. For example, the Higher Education Innovation Fund (HEIF) was specifically devised to encourage and support universities' engagement in KE activities, the allocation of HEIF based solely on universities' incomes generated from KE activities (PACEC, 2012), suggesting that universities are incentivised to increase their KE activities. Universities that receive HEIF are also now required to outline their strategies in relation to KE activities (PACEC, 2017). These policy contexts may help explain the broader strategic focus of certain universities, given that a narrower focus would seem to pay greater rewards to the university itself. Universities also, however, clearly have different levels of capabilities to engage in $\mathrm{KE}$ activities. Their KE capabilities are likely to be a function of several factors such as universities' research quality, size, age, specialisation, and past experience. As Sengupta and Ray (2017a, 
p. 706) noted, "specialized universities limited by the number of research-active disciplines would prefer channels involving AE [academic engagement], whereas those with a broader research focus discriminate between channels of $\mathrm{RC}$ [research commercialisation] or $\mathrm{AE}$ to a lesser degree". In other words, the breadth of universities' research focus determines the range of their KE activities. It has also been found that the presence of more applied disciplines (i.e., engineering or bio-medicine) positively influence universities' tendency to engage in $\mathrm{KE}$ activities (Bekkers and Bodas Freitas, 2008).

\section{$* * *$ Table $2 * * *$}

The context of devolution also highlights potential roles of differential government Higher Education policy for the three nations of the UK that can all be considered geographically peripheral but who have very different combinations of university types. Looking at Scotland 4 of the 9 universities with a KE focus are part of the TRF grouping, 4 in the IPERF, and one in the BF (with the 9 others part of the WEEI group). For Northern Ireland, whilst 2 of the universities are WEEI, one is IPERF and one BF. For Wales, however, whilst 5 universities are designated as WEEI, one is part of the IPERF group whilst 2 are members of the TRF cluster, with none in the BF category.

\subsection{Strategic priorities for KE activities}

This research also raises an important question of whether the large number of universities that have weak external entrepreneurial income generating Activities with SMEs should be encouraged to enhance such activities. It may be more efficient for them to adopt strategies that prioritize areas that they have a relative comparative advantage, in the geographies that they have the capacity to serve. The results in the table above, for example, indicate that universities with relatively weak External Entrepreneurial Income generating Activities with SMEs are significantly more strategically focused on activities that Morgan (2002) conceptualised as 
outreach, in terms of human (social) capital development, but only compared to the university group focused on Software licence income / non software licence income / Contract research, and sales of shares in spinoffs.

Where universities have a narrow focus but the region they reside within is attempting to transition towards more core and away from peripheral economy status, this may also suggest the need for government policy able to utilise the strengths of universities that focus on different strategic areas, in combination. More generally, these results suggest, however, that at least in terms of strategies with regards to income generation with SME the dichotomy between 'elite' and 'outreach' universities, overlapping with Hewitt-Dundas's (2012) Low Research Intensive /High Research Intensive definition is too simplistic, with policy development in this area requiring in-depth analysis of universities' strategic focus prior to the development of linking multiple universities together to promote more beneficial entrepreneurial ecosystem outcomes.

\section{Limitation and future research}

Clearly this research has a number of limitations, broadly the prescriptive power limited due to the cross-sectional data, though offering a starting point for further research on the topic. More specifically, first, this study is based on one year of data, and a more longitudinal approach would be valuable. Second, this study is within the UK context only, and research into a range of international contexts would also help develop this area. Third, whilst we have been able to map the outcomes of strategic choices in terms of the KE activities focused on, we have not analysed in detail the individual level university reasons that might explain this, including underlying strategies. Fourth, the insights that come out from the data are based on a crosssectional analysis of those universities that currently have income coming from KE, meaning that this approach is not able to evaluate longitudinal transitional processes towards more 
entrepreneurial universities, particularly in cases where there is no substantial income from the analysed activities. Nor have we undertaken a detailed evaluation of the regional economic context in which the university sits. More in depth analysis of the factors underlying universities strategic choices would therefore seem to be the most fruitful area for future research.

\section{Conclusions}

The research undertaken in the paper examined the outcomes from universities' KE strategies with specific regards to interaction with SMEs, creating an index and ranking of universities, but also identifying specific groupings of universities defined by different combinations and strengths of the individual KE activities from which the overall rankings are derived. The contribution to knowledge concerning the Entrepreneurial University has been built, therefore, by extending the existing literature on university archetypes and rankings (most notably Morgan, 2002; Hewitt-Dundas, 2012; Abreu et al., 2016, Fuller et al., 2017) through more detailed, University-SME interactions specific analysis, of a broad range of University KE activities. This allows a more fine grained definition of Entrepreneurial Universities than previously, by simultaneously being able to evaluate their overall strength, range, focus, and combination, allowing identification of the diverse strategies different universities employ to obtain similar results in terms of outcomes.

Specifically, it identifies that entrepreneurial universities valorize university knowledge assets through concentration on five SME-focused KE activities most beneficial to measuring the entrepreneurial university, namely Consultancy for SMEs, CPD for SMEs Software licence income, non-software licence income and contract research. It finds 4 different archetypal categories (groupings) of universities on the GAIA plane that can be visually identified from Weak External Entrepreneurial Income generating Activities with SMEs; CPD / Consultancy / 
Facilities focused; Software licence income / non software licence income / Contract research, and sales of shares in spinoffs focused; and Broadly focused. Identifying the most relevant KE activities (both singular and in combination) that universities are using, in relation to the entrepreneurial university concept as it relates to interactions with SMEs, Universities more narrowly focused on Software licence income / non software licence income / Contract research, and sales of shares in spinoffs focused are those broadly with the highest Entrepreneurial University ranking.

The results also suggest that the specific SME-focused entrepreneurial university archetype likely to be beneficial regional economic development in terms of shaping entrepreneurial ecosystems will likely depend on the ecosystem itself. Implications of the findings for key stakeholders include a potential need for government Higher Education policy to take account of the different mixes of university archetypes that exist in a region, when considering how best higher education can support regional policy goals. This is also particularly relevant when considering how to support SMEs, as key stakeholders and developers of regional entrepreneurial ecosystems. 


\section{Reference}

Abreu, M., Demirel, P., Grinevich, V. and Karatas-Özkan, M. (2016), "Entrepreneurial practices in research-intensive and teaching-led universities", Small Business Economics, Vol. 47 No. 3, pp. 695-717.

Abreu, M. and Grinevich, V. (2013), "The nature of academic entrepreneurship in the UK: Widening the focus on entrepreneurial activities", Research Policy, Vol. 42 No. 2, pp. 408-422.

Audretsch, D.B. (2014), "From the entrepreneurial university to the university for the entrepreneurial society”, The Journal of Technology Transfer, Vol. 39 No. 3, pp. 313321.

Behzadian, M., Kazemzadeh, R.B., Albadvi, A. and Aghdasi, M. (2010), "PROMETHEE: A comprehensive literature review on methodologies and applications", European Journal of Operational Research, Vol. 200 No. 1, pp. 198-215.

Bekkers, R. and Freitas, I.M.B. (2008), “Analysing knowledge transfer channels between universities and industry: To what degree do sectors also matter?", Research Policy, Vol. 37 No. 10, pp. 1837-1853.

BIS. (2010), "Internationalisation of Innovative and High Growth SMEs. BIS ECONOMICS PAPER NO. 5”, Department for Business Innovation and Skills, p. 132.

Bonaccorsi, A., Daraio, C., Lepori, B. and Slipersæter, S. (2007), "Indicators on individual higher education institutions: addressing data problems and comparability issues", Research Evaluation, Vol. 16 No. 2, pp. 66-78.

Bonner, K., Hewitt-Dundas, N. and Roper, S. (2015), “Collaboration between SMEs and Universities”, Enterprise Research Centre, p. 55.

Brans J-P. (1982), “L'inge'nierie de la de'cision: elaboration d'instruments d'aide a' la de'cision”. In: Nadeaeu R, Landry M (eds) L'aide a la de'cision: nature, instruments et perspectives d'avenir. Presse de l'Universite' de Laval, Que'bec, 183-213.

Brans, J.-P. and Mareschal, B. (1994), “The PROMCALC \& GAIA decision support system for multicriteria decision aid”, Decision Support Systems, Vol. 12 No. 4-5, pp. 297-310.

Brans, J.-P. and Mareschal, B. (2005), "PROMETHEE methods" in Figueira, J., Greco, S. and Ehrgott, M. (eds.), Multiple Criteria Decision Analysis: State of the Art Surveys, Springer, New York, pp. 187-219. 
Brans, J.-P. and Vincke P. (1985), “A preference ranking organisation method: The PROMETHEE method for multiple criteria decision-making”, Management Science, Vol. 31 No. 6, pp. 647-656.

Bronstein, J. and Reihlen, M. (2014), "Entrepreneurial university archetypes: A meta-synthesis of case study literature", Industry and Higher Education, Vol. 28 No. 4, pp. 245-262.

Charles, D., Kitagawa, F. and Uyarra, E. (2014), "Universities in crisis? - new challenges and strategies in two English city-regions", Cambridge Journal of Regions, Economy and Society, Vol. 7 No. 2, pp. 327-348.

Clifton, N., Keast, R., Pickernell, D. and Senior, M. (2010), "Network Structure, Knowledge Governance, and Firm Performance: Evidence from Innovation Networks and SMEs in the UK”, Growth and Change, Vol. 41 No. 3, pp. 337-373.

Colyvas, J.A. (2007), "From divergent meanings to common practices: The early institutionalization of technology transfer in the life sciences at Stanford University", Research Policy, Vol. 36 No. 4, pp. 456-476.

Cooke, P. (2003), “The Regional Innovation System in Wales: Evolution or Eclipse”, in: Cooke P, Heidenreich, M. and Braczyk, H. (eds), Regional Innovation Systems, 2nd Edition, Routledge, London, pp. 214-233.

Day, A. and Fernandez, R. (2015), "Strategies for sustaining growth of income from knowledge exchange across Higher Education Institutions (HEIs) in the UK", available at: https://www.praxisunico.org.uk/sites/praxisunico.org.uk/files/NCUB_Strategies\%20for \%20Sustaining\%20Growth\%20of\%20Income.pdf (accessed 3 June 2018).

D'Este, P. and Patel, P. (2007), "University-industry linkages in the UK: What are the factors underlying the variety of interactions with industry?", Research Policy, Vol. 36 No. 9, pp. $1295-1313$.

Etzkowitz, H., Webster, A., Gebhardt, C. and Terra, B.R.C. (2000), "The future of the university and the university of the future: evolution of ivory tower to entrepreneurial paradigm”, Research Policy, Vol. 29 No. 2, pp. 313-330.

Fini, R., Grimaldi, R., Santoni, S. and Sobrero, M. (2011), "Complements or substitutes? The role of universities and local context in supporting the creation of academic spin-offs", Research Policy, Vol. 40 No. 8, pp. 1113-1127.

Fini, R., Rasmussen, E., Siegel, D. and Wiklund, J. (2018), "Rethinking the commercialization of public science: from entrepreneurial outcomes to societal impacts", Academy of Management Perspectives, Vol. 32 No. 1, pp. 4-20. 
Fuller, D., Beynon, M. and Pickernell, D. (2017), "Indexing third stream activities in UK universities: exploring the entrepreneurial/enterprising university", Studies in Higher Education, Vol. 44 No.1, pp. 1-25.

Galán-Muros, V. and Plewa, C. (2016), "What drives and inhibits university-business cooperation in Europe? A comprehensive assessment", $R \& D$ Management, Vol. 46 No. 2, pp. 369-382.

Giuliani, E. and Arza, V. (2009), "What Drives the Formation of 'Valuable' University Industry Linkages? Insights from the Wine Industry", Research Policy, Vol. 38 No. 6, pp. 906-21.

Guerrero, M., Cunningham, J.A. and Urbano, D. (2015), "Economic impact of entrepreneurial universities' activities: An exploratory study of the United Kingdom”, Research Policy, Vol. 44 No. 3, pp. 748-764.

Guerrero, M. and Urbano, D. (2012), "The development of an entrepreneurial university", The Journal of Technology Transfer, Vol. 37 No. 1, pp. 43-74.

Guerrero, M., Urbano, D., Fayolle, A., Klofsten, M. and Mian, S. (2016), "Entrepreneurial universities: emerging models in the new social and economic landscape", Small Business Economics, Vol. 47 No. 3, pp. 551-563.

Halouani, N., Chabchoub, H. and Martel, J.-M. (2009), "PROMETHEE-MD-2T method for project selection”, European Journal of Operational Research, Vol. 195 No. 3, pp. 841849.

HE-BCI Report. (2017), “Higher Education - Business and Community Interaction Survey 2015-16.”, Department for Business, Energy \& Industrial Strategy, p. 42.

Hewitt-Dundas, N. (2012), "Research intensity and knowledge transfer activity in UK universities”, Research Policy, Vol. 41 No. 2, pp. 262-275.

Hmieleski, K.M. and Powell, E.E. (2018), “The psychological foundations of university science commercialization: A review of the literature and directions for future research", Academy of Management Perspectives, Vol. 32 No. 1, pp. 43-77.

Huggins, R., Johnston, A. and Stride, C. (2012), "Knowledge networks and universities: Locational and organisational aspects of knowledge transfer interactions", Entrepreneurship \& Regional Development, Vol. 24 No. 7-8, pp. 475-502.

Ishizaka, A. and Nemery, P. (2011), "Selecting the best statistical distribution with PROMETHEE and GAIA", Computers \& Industrial Engineering, Vol. 61 No. 4, pp. 958-969. 
Kitagawa, F., Barrioluengo, M.S. and Uyarra, E. (2016), "Third mission as institutional strategies: Between isomorphic forces and heterogeneous pathways", Science \& Public Policy, Vol. 43 No. 6, pp. 736-750.

Lambert, R. (2003), “Lambert Review of Business-University Collaboration”, available at: http://www.hm-treasury.gov.uk/media//EA556/lambert_review_final_450.pdf (accessed 25 June 2018).

Louis, K.S., Blumenthal, D., Gluck, M.E. and Stoto, M.A. (1989), "Entrepreneurs in academe: An exploration of behaviors among life scientists", Administrative Science Quarterly, Vol. 34 No. 1, pp. 110-131.

Mareschal, B., De Smet, Y. and Nemery, P. (2008), "Rank reversal in the PROMETHEE II method : Some new results", in IEEE 2008 International Conference on Industrial Engineering and Engineering Management, Singapore, 2008, pp. 959-963.

Martin, B.R. (2012), "Are universities and university research under threat? Towards an evolutionary model of university speciation", Cambridge Journal of Economics, Vol. 36 No. 3, pp. 543-565.

Mason, C. and Brown, R. (2013), "Creating good public policy to support high-growth firms", Small Business Economics, Vol. 40 No. 2, pp. 211-225.

McCormack, J., Propper, C. and Smith, S. (2014), "Herding cats? Management and university performance", The Economic Journal, Vol. 124 No. 578, pp. 534-564.

Miller, K., McAdam, M. and McAdam, R. (2014), “The changing university business model: a stakeholder perspective", $R \& D$ Management, Vol. 44 No. 3, pp. 265-287.

Morgan, B. (2002), "Higher Education and Regional Economic Development in Wales: An Opportunity for Demonstrating the Efficacy of Devolution in Economic Development", Regional Studies, Vol. 36 No. 1, pp. 65-73.

Mowery, D., Nelson, R., Sampat, B. and Ziedonis, A. (2015), Ivory Tower and Industrial Innovation University-Industry Technology Transfer before and after the Bayh-Dole Act, Stanford University Press, California.

Nemery, P., Ishizaka, A., Camargo, M. and Morel, L. (2012), "Enriching descriptive information in ranking and sorting problems with visualizations technique", Journal of Modelling in Management, Vol. 7 No. 2, pp. 130-147.

Olmos-Peñuela, J., Castro-Martínez, E. and D’Este, P. (2014), “Knowledge transfer activities in social sciences and humanities: Explaining the interactions of research groups with non-academic agents", Research Policy, Vol. 43 No. 4, pp. 696-706. 
PACEC. (2017), "The State of the English University Knowledge Exchange Landscape”, available at: https://dera.ioe.ac.uk/29698/1/2017_kelandscape_.pdf (accessed 31 May 2018).

PACEC. (2012), "Strengthening the Contribution of English Higher Education Institutions to the Innovation System: Knowledge Exchange and HEIF Funding”, available at: https://ec.europa.eu/futurium/en/system/files/ged/48-pacec-

publiccoroporateeconomicconsultants_-_km_exchange_and_heif_funding-_11-15-

fullreport.pdf (accessed 1 June 2018).

PACEC/CBR. (2009), "Evaluation of the Effectiveness and Role of HEFCE/OSI Third Stream Funding”, available at: https://www.cbr.cam.ac.uk/fileadmin/user_upload/centre-forbusiness-research/downloads/special-reports/specialreportevaluationeffectivenesshefce.pdf (accessed 17 May 2018).

Perkmann, M., Tartari, V., McKelvey, M., Autio, E., Broström, A., D’Este, P., and Fini, R. (2013), "Academic engagement and commercialisation: A review of the literature on university-industry relations", Research Policy, Vol. 42 No. 2, pp. 423-442.

Philpott, K., Dooley, L., O’Reilly, C. and Lupton, G. (2011), “The entrepreneurial university: Examining the underlying academic tensions", Technovation, Vol. 31 No. 4, pp. 161170.

Ramos-Vielba, I., Sánchez-Barrioluengo, M. and Woolley, R. (2016), "Scientific research groups' cooperation with firms and government agencies: motivations and barriers", The Journal of Technology Transfer, Vol. 41 No. 3, pp. 558-585.

Rosli, A. and Rossi, F. (2016), "Third-mission policy goals and incentives from performancebased funding: Are they aligned?", Research Evaluation, Vol. 25 No. 4, pp. 427-441.

Sam, C. and Sijde, P. (2014), "Understanding the concept of the entrepreneurial university from the perspective of higher education models", Higher Education, Vol. 68 No. 6, pp. 891908.

Sánchez-Barrioluengo, M. (2014), “Articulating the 'three-missions' in Spanish universities”, Research Policy, Vol. 43 No. 10, pp. 1760-1773.

Schwartz, M. and Göthner, M. (2009), “A multidimensional evaluation of the effectiveness of business incubators: An application of the PROMETHEE outranking method", Environment and Planning C: Government and Policy, Vol. 27 No. 6, pp. 1072-1087. 
Sengupta, A. and Ray, A. (2017a), "Choice of structure, business model and portfolio: organizational models of knowledge transfer offices in British Universities", British Journal of Management, Vol. 28 No. 4, pp. 687-710.

Sengupta, A. and Ray, A. (2017b), "University research and knowledge transfer: A dynamic view of ambidexterity in British universities", Research Policy, Vol. 46 No. 5, pp. 881897.

Tofallis, C. (2008), "Selecting the best statistical distribution using multiple criteria", Computers \& .Industrial Engineering, Vol. 54 No. 3, pp. 690-694.

Zhang, Q., Mackenzie, N.G., Jones-evans, D. and Huggins, R. (2016), “Leveraging knowledge as a competitive asset? The intensity, performance and structure of universities' entrepreneurial knowledge exchange activities at a regional level", Small Business Economics; Dordrecht, Vol. 47 No. 3, pp. 657-675.

Živković, Ž., Nikolić, D., Savić, M., Djordjević, P. and Mihajlović, I. (2017), "Prioritizing Strategic Goals in Higher Education Organizations by Using a SWOTPROMETHEE/GAIA-GDSS Model”, Group Decision \& Negotiation, Vol. 26 No. 4, pp. 829-846. 
Table 1: PROMETHEE Ranking of University KE Activity with SMEs

\begin{tabular}{|c|c|c|c|c|}
\hline Rank & University & Positive & Negative & Net Flows \\
\hline 1 & A104-The University of Oxford & 0.328903 & 0.016645 & 0.312257 \\
\hline 2 & A150-University College London & 0.241222 & 0.018694 & 0.222528 \\
\hline 3 & A134-The University of Southampton & 0.190443 & 0.01754 & 0.172903 \\
\hline 4 & A75-The University of Leeds & 0.192261 & 0.023024 & 0.169238 \\
\hline 5 & A28-Cardiff University & 0.18752 & 0.02039 & 0.16713 \\
\hline 6 & A82-The University of Liverpool & 0.175388 & 0.019949 & 0.15544 \\
\hline 7 & A25-The University of Cambridge & 0.165584 & 0.016382 & 0.149202 \\
\hline 8 & A93-The University of Manchester & 0.165573 & 0.018485 & 0.147088 \\
\hline 9 & A42-The University of Dundee & 0.165283 & 0.029018 & 0.136264 \\
\hline 10 & A1-The University of Aberdeen & 0.155824 & 0.027097 & 0.128727 \\
\hline 11 & A100-University of Nottingham & 0.145663 & 0.019962 & 0.125702 \\
\hline 12 & A128-The University of Salford & 0.134909 & 0.024853 & 0.110056 \\
\hline 13 & A4-Anglia Ruskin University & 0.13382 & 0.025011 & 0.108809 \\
\hline 14 & A162-The University of York & 0.130857 & 0.023146 & 0.107712 \\
\hline 15 & A123-The Royal Veterinary College & 0.128847 & 0.021805 & 0.107042 \\
\hline 16 & A142-The University of Surrey & 0.119407 & 0.026165 & 0.093242 \\
\hline 17 & A130-SRUC & 0.119677 & 0.033772 & 0.085904 \\
\hline 18 & A62-Heriot-Watt University & 0.107128 & 0.027541 & 0.079586 \\
\hline 19 & A72-The University of Lancaster & 0.082719 & 0.024117 & 0.058601 \\
\hline 20 & A67-Imperial College & 0.076513 & 0.028208 & 0.048305 \\
\hline 21 & A132-The University of Sheffield & 0.072786 & 0.028503 & 0.044283 \\
\hline 22 & A37-Cranfield University & 0.067664 & 0.025258 & 0.042406 \\
\hline 23 & A107-The University of Portsmouth & 0.064812 & 0.025725 & 0.039087 \\
\hline 24 & A102-The Open University & 0.069556 & 0.030993 & 0.038563 \\
\hline 25 & A70-King's College London & 0.061255 & 0.022893 & 0.038362 \\
\hline 26 & A50-The University of Exeter & 0.062538 & 0.024221 & 0.038317 \\
\hline 27 & A152-The University of Warwick & 0.062805 & 0.027009 & 0.035797 \\
\hline 28 & A12-Birmingham City University & 0.066685 & 0.031426 & 0.035259 \\
\hline 29 & A48-The University of Edinburgh & 0.063653 & 0.02973 & 0.033923 \\
\hline 30 & A21-The University of Bristol & 0.05599 & 0.026207 & 0.029783 \\
\hline
\end{tabular}


Table 2: Comparisons of Means between different cluster groupings: For Top 3 Selected Strategic Priorities of UK Universities Related to Entrepreneurial / Innovation Ecosystems identified in HE-BCI Report (2017).

\begin{tabular}{|l|l|l|l|l|l|l|l|}
\hline University Grouping & $\begin{array}{l}\text { Widening } \\
\text { Participation }\end{array}$ & $\begin{array}{l}\text { Graduate } \\
\text { Retention in } \\
\text { Local } \\
\text { Region }\end{array}$ & $\begin{array}{l}\text { Supporting } \\
\text { SMES }\end{array}$ & $\begin{array}{l}\text { Graduate } \\
\text { Enterprise }\end{array}$ & $\begin{array}{l}\text { Incubator } \\
\text { Provision }\end{array}$ & $\begin{array}{l}\text { Attracting } \\
\text { Students } \\
\text { to Region }\end{array}$ & $\begin{array}{l}\text { Regional } \\
\text { Skills } \\
\text { Needs }\end{array}$ \\
\hline $\begin{array}{l}\text { 1) } \begin{array}{l}\text { Weak External } \\
\text { Income generating } \\
\text { Activities with SMEs }\end{array} \\
\text { 2) CPD / Consultancy / } \\
\text { Facilities focused }\end{array}$ & $0.4513(3,4)$ & $0.1947(3)$ & $0.2743(4)$ & $0.1327(3)$ & 0.0354 & $0.2124(3)$ & $0.2301(3)$ \\
\hline $\begin{array}{l}\text { 3) Software licence } \\
\text { income / non software } \\
\text { licence income / Contract } \\
\text { research, and sales of } \\
\text { shares in spinoffs focused }\end{array}$ & 0.1333 & 0.0435 & $0.4348(4)$ & 0.0807 & 0.1304 & 0.0807 & 0.2609 \\
\hline $\begin{array}{l}\text { 4) Broadly focused } \\
\text { S }\end{array}$ & 0.0909 & 0.1818 & 0.00000 & 0.0909 & 0.1818 & 0.0909 & 0.1818 \\
\hline
\end{tabular}

Note: Figures in parentheses refer to significant at $5 \%$ level Tamhane Tests 


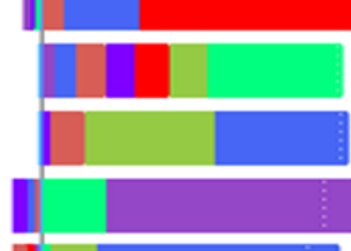

A25-The University of Cambridge A93-The University of Manchester A42-The University of Dundee

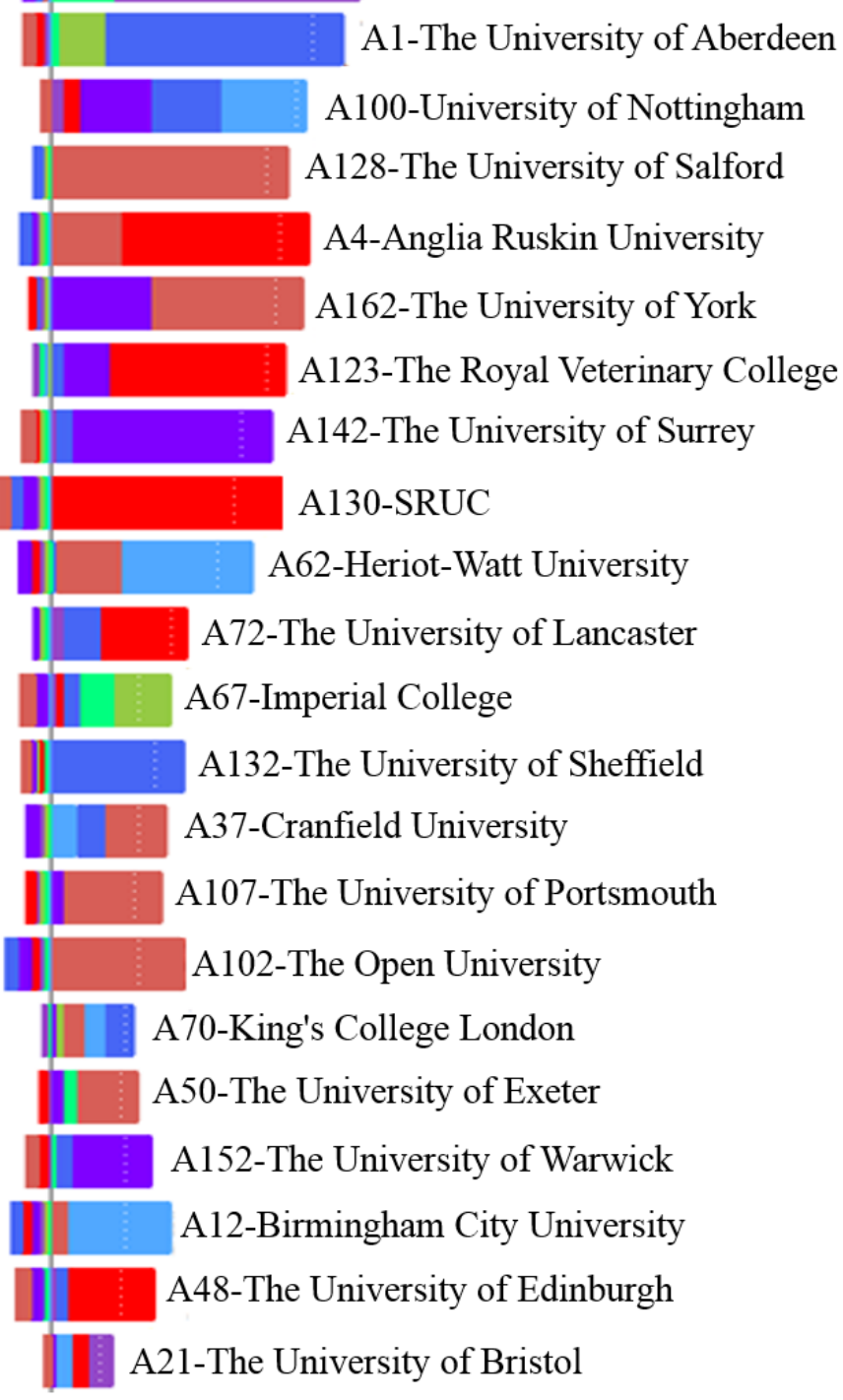

software licence income
non-software licence income
sale of shares in spinouts
contract research income
consultancy income
facilities \& equipment
related services
other intellectual property
(IP) income
continuous professional
development (CPD)

Figure 1: PROMETHEE Scores by Variable 


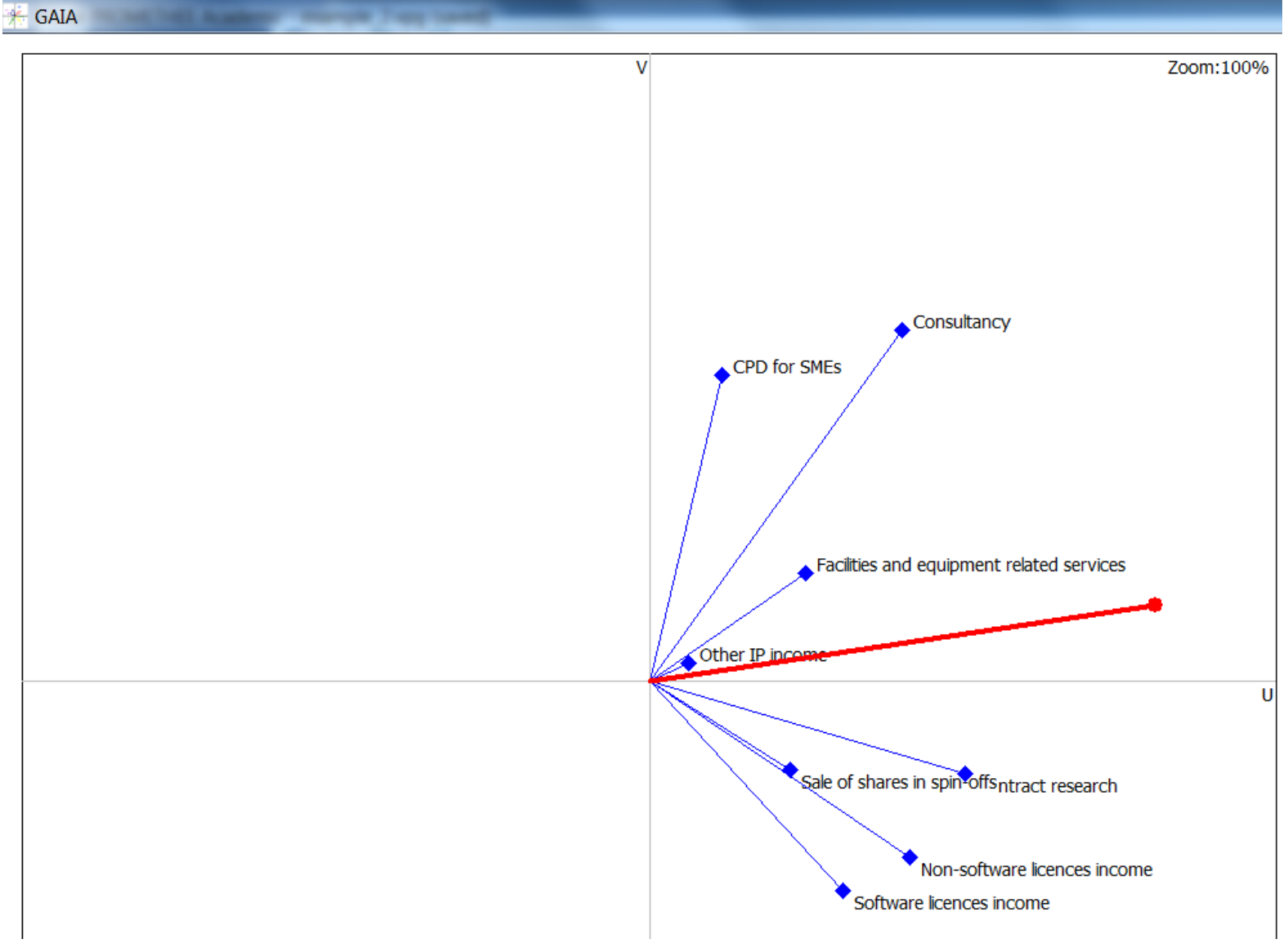

Figure 2: The GAIA plane analysis for knowledge exchange activities 


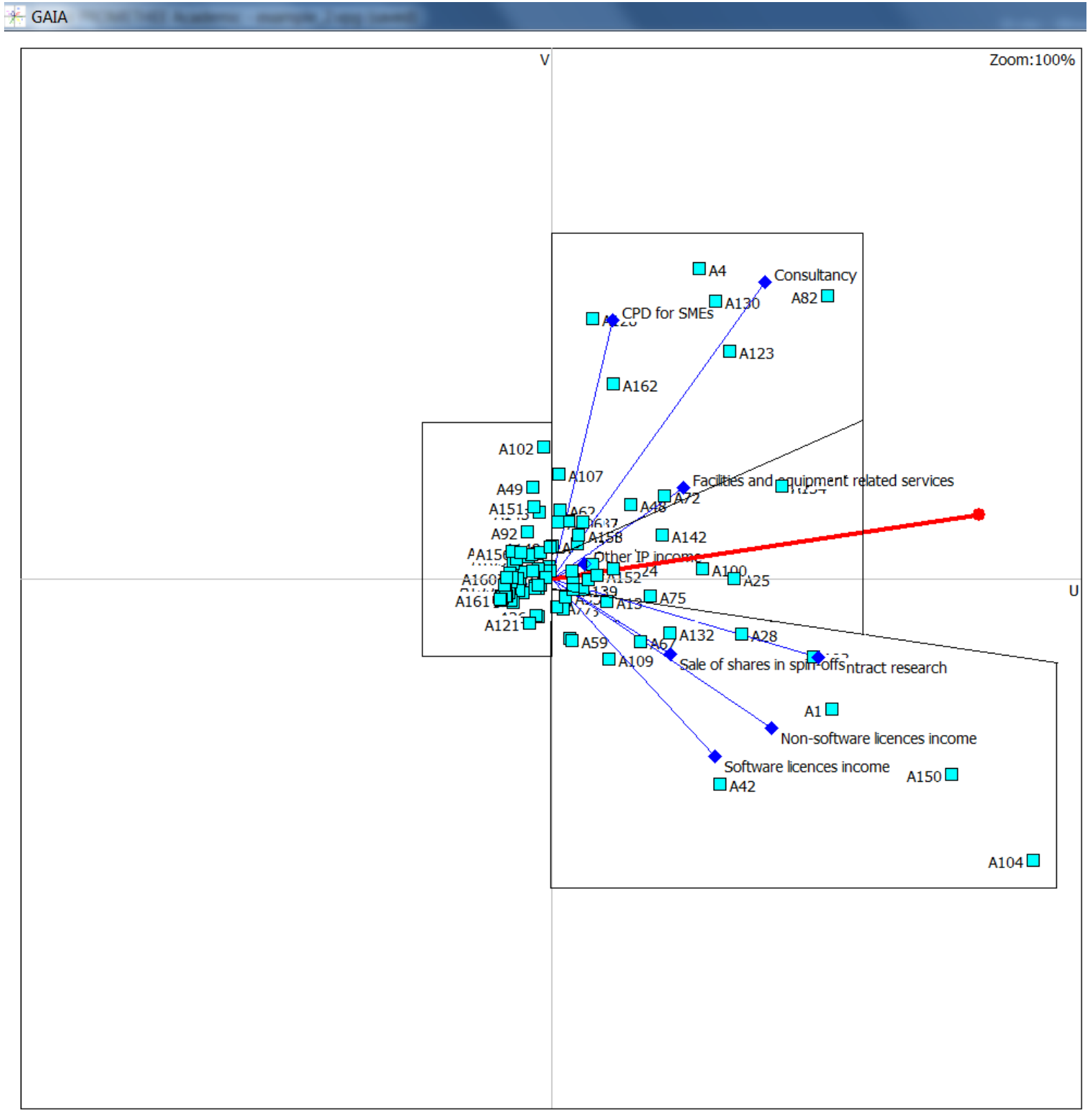

Figure 3: Groupings of universities 